\title{
Effect of Nodes Mobility using different Trajectories
}

\author{
Arshdeep Singh Baath \\ Research Scholar, Department of ECE, \\ SBSSTC , Ferozepur-152004, Punjab ,India.
}

\author{
Amit Grover \\ Assistant Professor, Department of ECE, \\ SBSSTC, Ferozepur-152004, Punjab, India.
}

\begin{abstract}
In this paper the effect of mobility of nodes at different trajectories have been analyzed on zigbee Mesh topology. Different Trajectories used are Helbert space-filling curve, hexagon trajectory and square trajectory. The effect is analyzed in terms of Throughput, Packet Loss and Media Access Delay. Results have been analyzed once by keeping 32 nodes fixed and all others moving at speed of $5 \mathrm{~m} / \mathrm{sec}$ and 7 $\mathrm{m} / \mathrm{sec}$ and secondly by moving 32 nodes at speed of $5 \mathrm{~m} / \mathrm{sec}$ and $7 \mathrm{~m} / \mathrm{sec}$ and keeping all other nodes fixed. When 32 nodes are kept fixed and all other nodes are moving it has been concluded that the hexagon trajectory performs better as compare to square trajectory. Further it has been investigated that when 32 nodes moves and all other nodes are kept fixed, the performance of square trajectory is better at speed of 5 $\mathrm{m} / \mathrm{sec}$ and the performance of helbert curve is better at speed of $7 \mathrm{~m} / \mathrm{sec}$.
\end{abstract}

\section{Keywords}

WSN, ZigBee, 802.15, OPNET

\section{INTRODUCTION}

Zigbee is a wireless sensor network standard which suited for the family of Low-Rate Wireless Personal Area Networks (LR-WPANs 250 Kbps), allowing network creation, management, and data transmission over a wireless channel with the highest possible energy savings [1]. The standard was produced by the ZigBee Alliance to meet the accompanying essential needs like minimal cost, Integrated insight for network set-up and message routing and simple establishment of ultra-low power utilization[2]. The Zigbee is based on the IEEE 802.15.4 standard, which employs a non- persistent Carrier Sense Multiple Access with Collision Avoidance (CSMA/CA) Medium Access Control (MAC) protocol and operates in the $2.4 \mathrm{GHz}$ band (similarly to the IEEE 802.11 standard[3]).

ZigBee nodes send out data in range of 10-75 meters, which is used the RF communication, to make this communication three types of ZigBee nodes are used i.e. coordinator, router, and end device[4,5].

ZigBee coordinator: In each sensor network only one coordinator node is used, to make a communication for ZigBee. This sensor node is responsible for initializing the network, select the suitable channel and permit other devices to connect to its network[6,7].

ZigBee Router: Router is used to pass a information data in sensor network, and also capable to connect to other router, or an end device. Router functions are only used in a ZigBee topology[6,7].

ZigBee End Device: These nodes utilize the communication in router or a coordinator. An end device connected to the network through either a router, or directly to the coordinator[6,7].

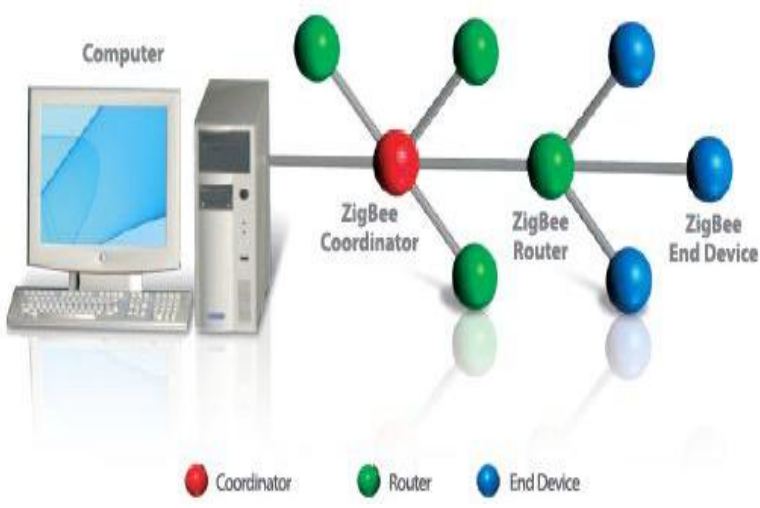

Fig 1: ZigBee Network

\section{MESH TOPOLOGIES}

In a network of mesh topology routers and coordinators shape various connections among one another while having enddevices as their children. While more perplexing in its development and operation, mesh topology is characterized by link/path redundancy which is known to in enhanced robustness and network routing capacity $[8,9,10,11]$.

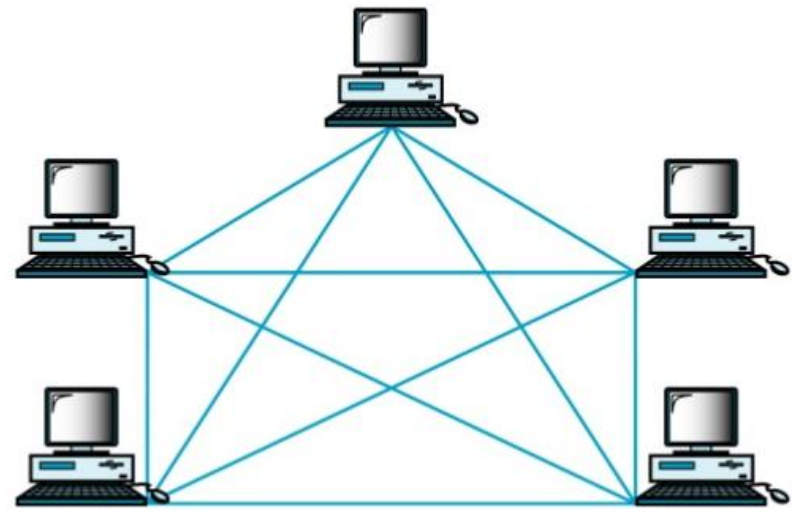

Fig 2: Mesh Topologies

\section{EXPERIMENTAL SETUP}

In this paper the effect of trajectories is analyzed on mesh topology. To analyze this effect different scenarios are used by using Helbert Space-filling curve[12,13,14], hexagon and outer square trajectory. In each scenarios 500 nodes are used which are placed randomly over an area of $2000 \mathrm{~m} * 2000 \mathrm{~m}$. In this area firstly 32 nodes are moving at different speed by using these trajectories and rest is static. In this scenarios nodes move and 8 nodes stoped at each points as shown in fig $3,4,5$ and rest moves further. In other scenario 32 nodes are static and other nodes are moving at different speed by using different trajectories. In these scenarios 468 nodes moves and 117 nodes stoped at each point as shown in fig 3,4,5 and rest moved for next point. In each scenario 4 mobile coordinator is used which moves at different speed by using different 
trajectories. These 4 coordinator moves and 1 coordinator stop at each point . In each scenario 32 routers are used which are placed randomly.

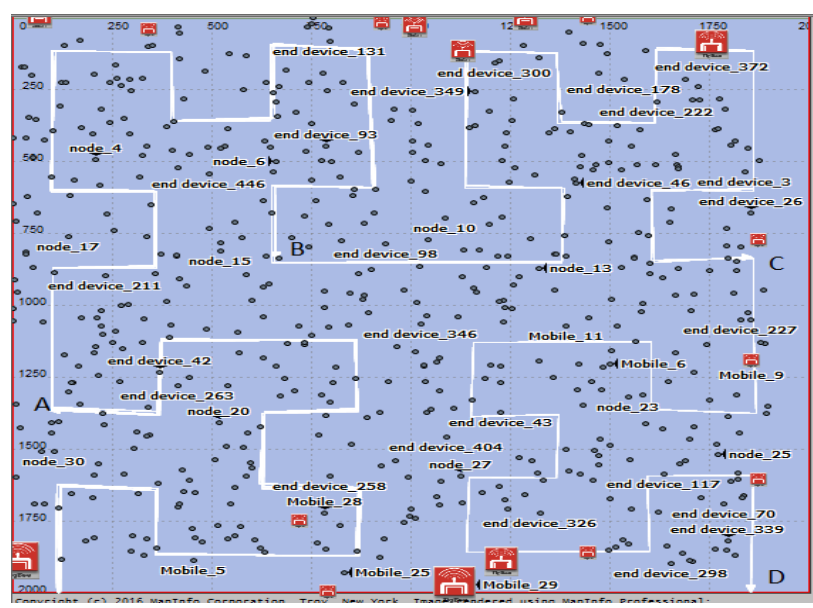

Fig 3: Helbert curve

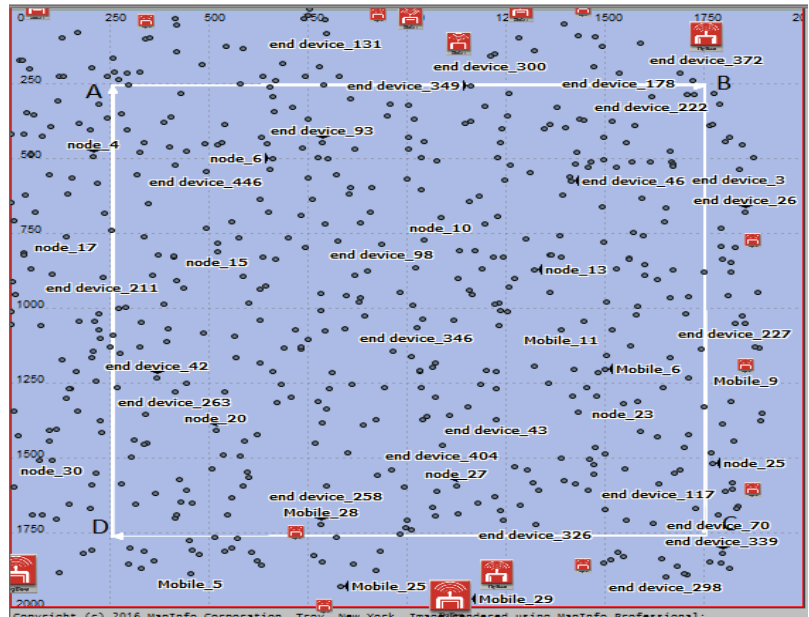

Fig 4: Square Trajectory

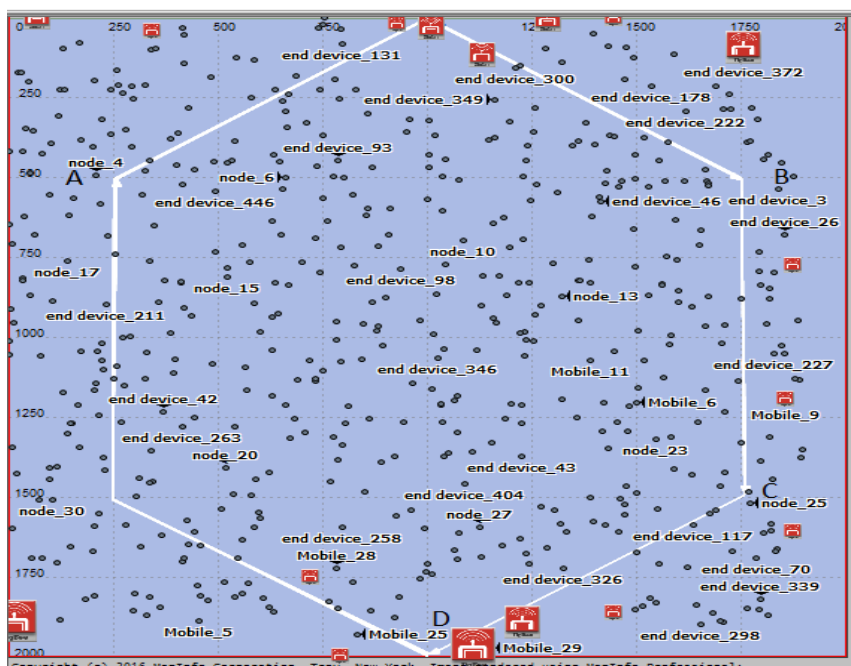

Fig 5: Hexagon Trajectory

\section{RESULTS}

Here performance of Mesh is analyzed with the mobility of both ZigBee End Devices and ZigBee coordinator for different trajectories. The result is analysed in terms of Packet loss, Throughput and Media Access Delay.

\subsection{Packet Loss}

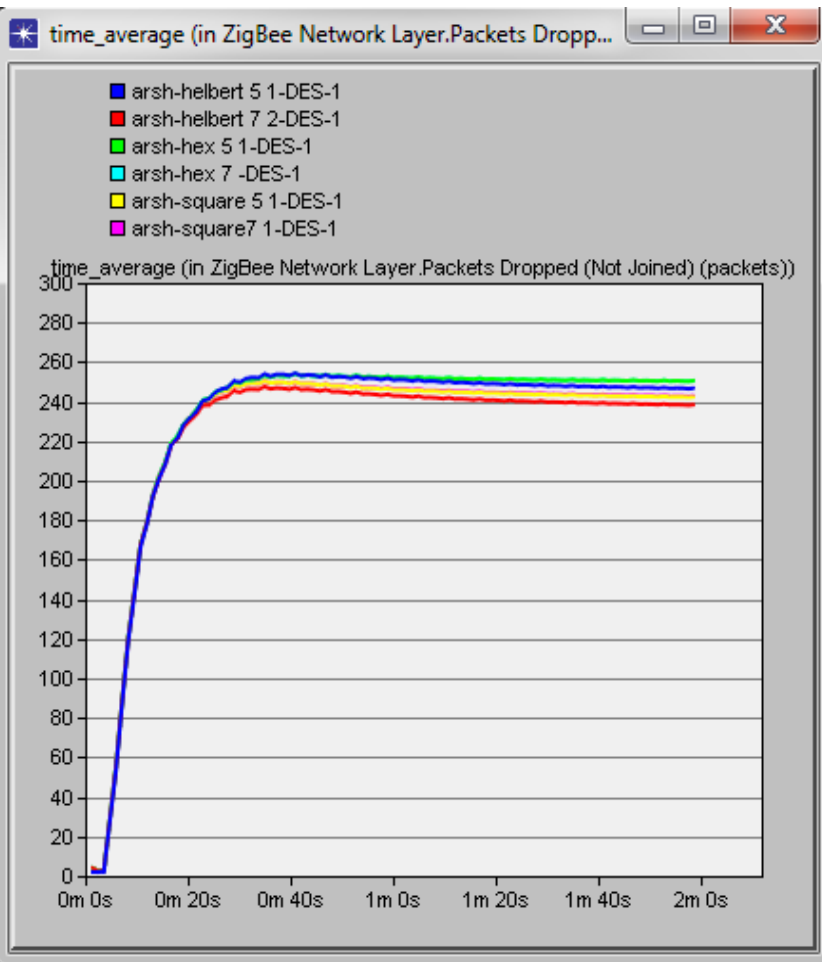

Fig 6:Packet loss when 32 nodes moves

* time_average (in ZigBee Network Layer.Packets Dropp... $\square$ 口

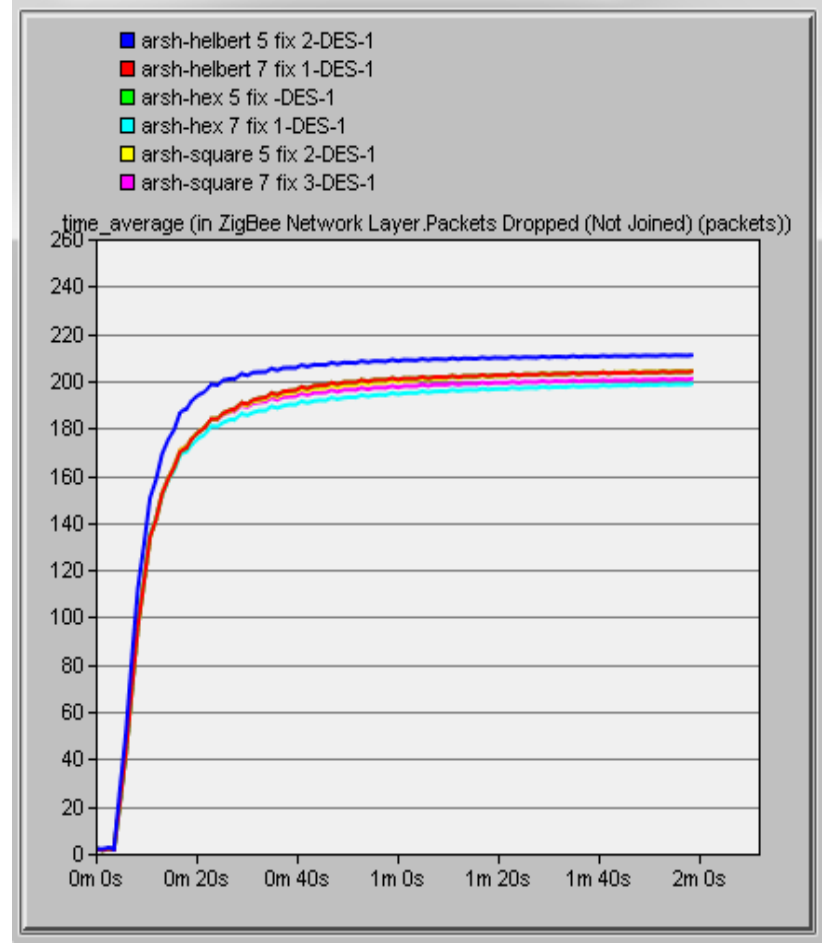

Fig 7:Packet loss when 32 nodes fix 
Fig6 shows the results of Packet loss for helbert curve, hexagon trajectory and square trajectory when 32 nodes moves with speed of $5 \mathrm{~m} / \mathrm{sec}$ and $7 \mathrm{~m} / \mathrm{sec}$ and all other nodes are fixed. Results shown in fig 5 are given in table 1.

Table 1: Packet loss when 32 nodes moves

\begin{tabular}{|l|l|l|l|}
\hline Speed & $\begin{array}{c}\text { Helbert } \\
\text { Curve } \\
\text { (Packet Loss) }\end{array}$ & $\begin{array}{c}\text { Hexagonal } \\
\text { Trajectory } \\
\text { (Packet Loss) }\end{array}$ & $\begin{array}{c}\text { Square } \\
\text { Trajec- } \\
\text { tory } \\
\text { (Packet } \\
\text { Loss) }\end{array}$ \\
\hline $5 \mathrm{~m} / \mathrm{sec}$ & $\begin{array}{l}246 \text { packets/ } \\
\text { Sec }\end{array}$ & $\begin{array}{l}250 \text { packets/ } \\
\text { sec }\end{array}$ & $\begin{array}{l}242 \\
\text { packets/ } \\
\text { sec }\end{array}$ \\
\hline $7 \mathrm{~m} / \mathrm{sec}$ & $\begin{array}{l}238 \\
\text { packets/ } \\
\text { Sec }\end{array}$ & $\begin{array}{l}250 \\
\text { packets/ } \\
\text { sec }\end{array}$ & $\begin{array}{l}242 \\
\text { packets/ } \\
\text { sec }\end{array}$ \\
\hline
\end{tabular}

Fig7 shows the results of Packet loss for helbert curve, hexagon trajectory and square trajectory when 32 nodes are fixed and all other nodes are moving with speed of $5 \mathrm{~m} / \mathrm{sec}$ and $7 \mathrm{~m} / \mathrm{sec}$. Results shown in fig 6 are given in table 2 .

Table 2: Packet loss when 32 nodes fix

\begin{tabular}{|c|l|l|l|}
\hline Speed & $\begin{array}{c}\text { Helbert } \\
\text { Curve } \\
\text { (Packet Loss) }\end{array}$ & $\begin{array}{c}\text { Hexagonal } \\
\text { Trajectory } \\
\text { (Packet Loss) }\end{array}$ & $\begin{array}{c}\text { Square } \\
\text { Trajec- } \\
\text { tory } \\
\text { (Packet } \\
\text { Loss) }\end{array}$ \\
\hline $5 \mathrm{~m} / \mathrm{sec}$ & $\begin{array}{l}210 \text { packets/ } \\
\text { Sec }\end{array}$ & $\begin{array}{l}204 \\
\text { packets/ } \\
\text { sec }\end{array}$ & $\begin{array}{l}204 \\
\text { packets/ } \\
\text { sec }\end{array}$ \\
\hline $7 \mathrm{~m} / \mathrm{sec}$ & $\begin{array}{l}204 \\
\text { packets/ }\end{array}$ & $\begin{array}{l}204 \\
\text { packets/ } \\
\text { sec }\end{array}$ & $\begin{array}{l}204 \\
\text { packets/ } \\
\text { sec }\end{array}$ \\
\hline
\end{tabular}

\subsection{Throughput}

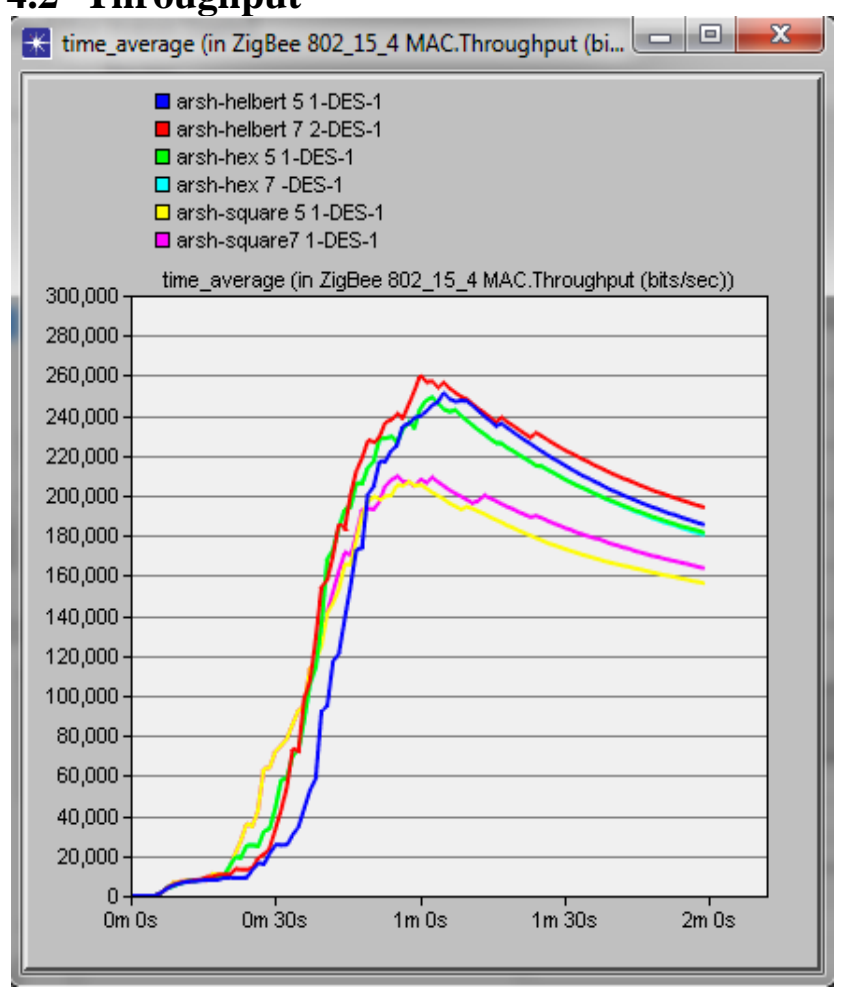

Fig 8:Throughput when 32 nodes moves

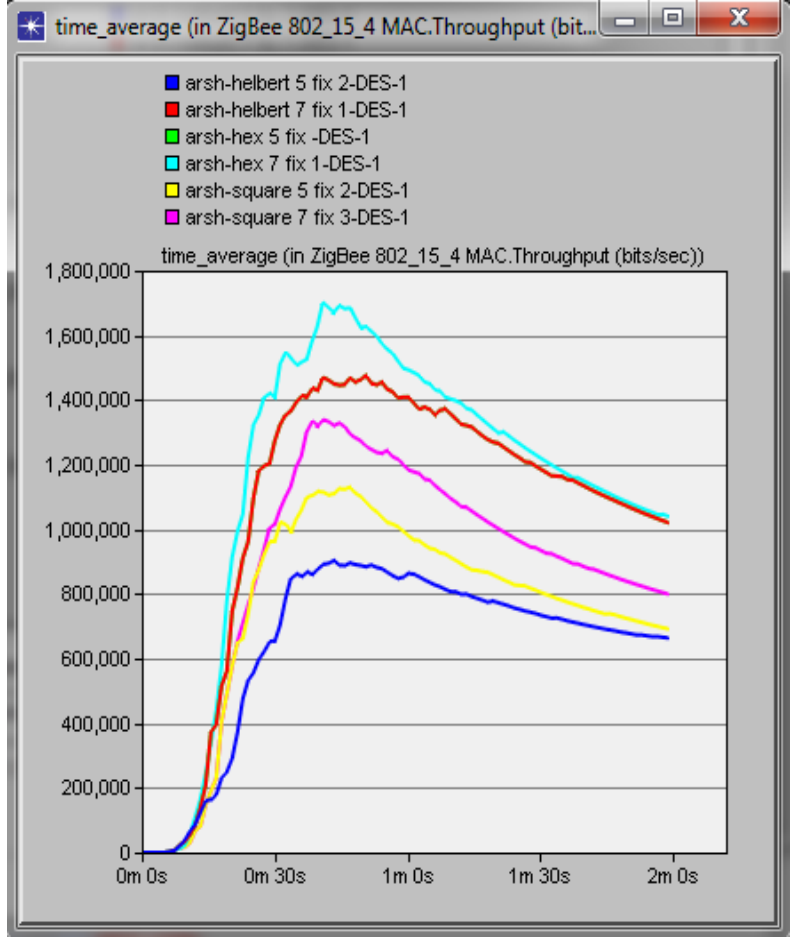

Fig 9:Throughput when 32 nodes Fix

Fig8 shows the results of Throughput for helbert curve, hexagon trajectory and square trajectory when 32 nodes moves with speed of $5 \mathrm{~m} / \mathrm{sec}$ and $7 \mathrm{~m} / \mathrm{sec}$ and all other nodes are fixed. Results shown in fig 7 are given in table3.

Table 3: Throughput when 32 nodes moves

\begin{tabular}{|l|l|l|l|}
\hline Speed & $\begin{array}{c}\text { Helbert } \\
\text { Curve } \\
\text { (Through- } \\
\text { put) }\end{array}$ & $\begin{array}{c}\text { Hexagonal } \\
\text { Trajectory } \\
\text { (Through-put) }\end{array}$ & $\begin{array}{c}\text { Square } \\
\text { Traject- } \\
\text { ory } \\
\text { (Throu- } \\
\text { gh- } \\
\text { put) }\end{array}$ \\
\hline $5 \mathrm{~m} / \mathrm{sec}$ & $\begin{array}{l}185,478 \\
\text { bits/sec }\end{array}$ & $\begin{array}{l}181,519 \\
\text { bits/sec }\end{array}$ & $\begin{array}{l}156,236 \\
\text { bits/sec }\end{array}$ \\
\hline $7 \mathrm{~m} / \mathrm{sec}$ & $\begin{array}{l}194,119 \\
\text { bits/sec }\end{array}$ & $\begin{array}{l}181,519 \\
\text { bits/sec }\end{array}$ & $\begin{array}{l}163,732 \\
\text { bits/sec }\end{array}$ \\
\hline
\end{tabular}

Fig9 shows the results of Throughput for helbert curve, hexagon trajectory and square trajectory when 32 nodes are fixed and all other nodes are moving with speed of $5 \mathrm{~m} / \mathrm{sec}$ and $7 \mathrm{~m} / \mathrm{sec}$. Results shown in fig 8 are given in table 4 .

Table 4: Throughput when 32 nodes fix

\begin{tabular}{|l|l|l|l|}
\hline Speed & $\begin{array}{c}\text { Helbert } \\
\text { Curve } \\
\text { (Through- } \\
\text { put) }\end{array}$ & $\begin{array}{c}\text { Hexagonal } \\
\text { Trajectory } \\
\text { (Through-put) }\end{array}$ & $\begin{array}{c}\text { Square } \\
\text { Traject- } \\
\text { ory } \\
\text { (Throu- } \\
\text { gh- } \\
\text { put) }\end{array}$ \\
\hline $5 \mathrm{~m} / \mathrm{sec}$ & $\begin{array}{l}663,440 \\
\text { bits/sec }\end{array}$ & $\begin{array}{l}1,020,176 \\
\text { bits/sec }\end{array}$ & $\begin{array}{l}691,765 \\
\text { bits/sec }\end{array}$ \\
\hline $7 \mathrm{~m} / \mathrm{sec}$ & $\begin{array}{l}1,020,176 \\
\text { bits/sec }\end{array}$ & $\begin{array}{l}1,020,176 \\
\text { bits/sec }\end{array}$ & $\begin{array}{l}799,234 \\
\text { bits } / \mathrm{sec}\end{array}$ \\
\hline
\end{tabular}




\subsection{Media Access Delay}

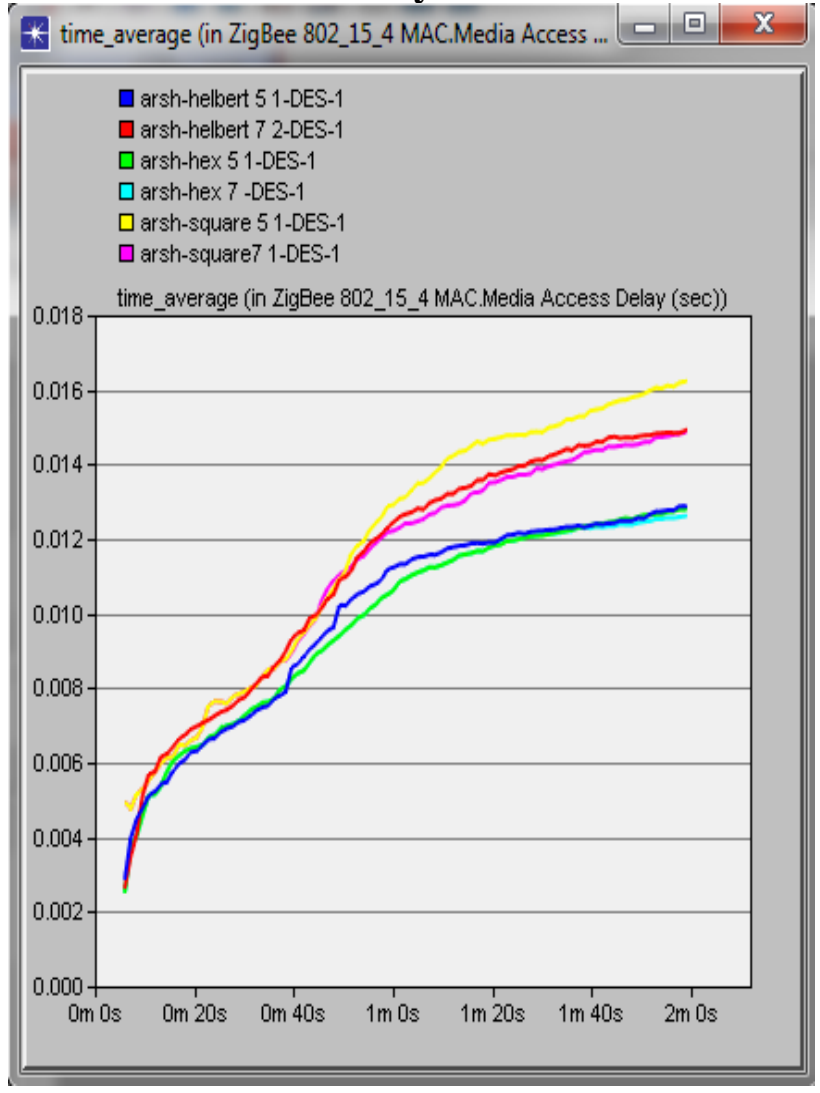

Fig 10: Media Access Delay when 32 nodes moves

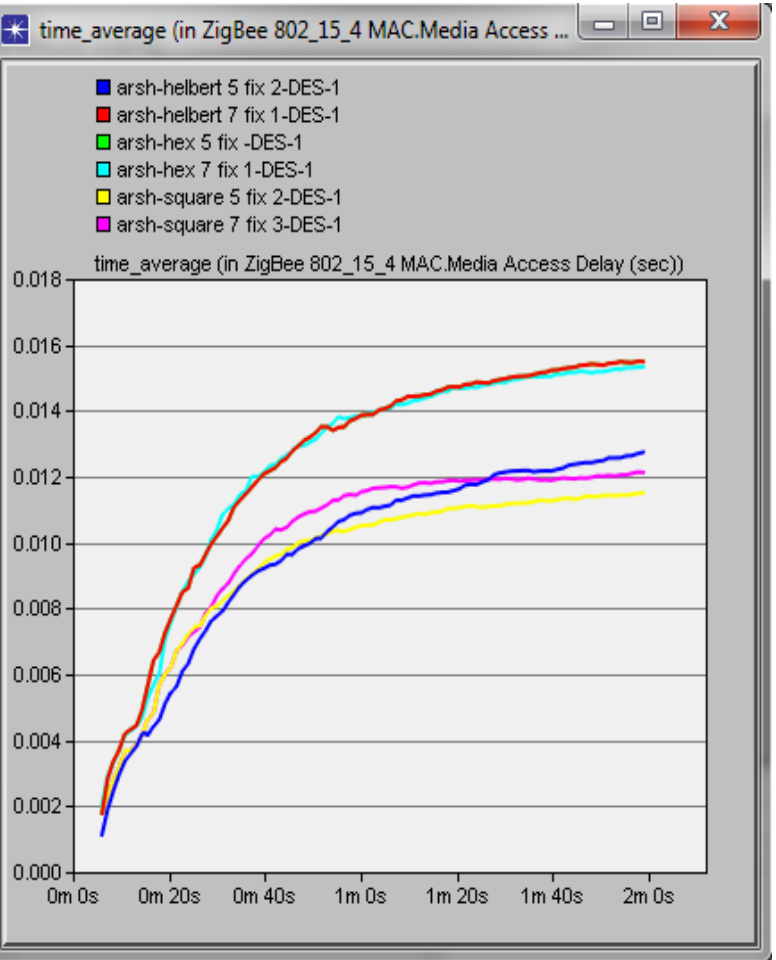

Fig 11: Media Access Delay when 32 nodes fix

Fig10 shows the results of Media Access Delay for helbert curve, hexagon trajectory and square trajectory when 32 nodes moves with speed of $5 \mathrm{~m} / \mathrm{sec}$ and $7 \mathrm{~m} / \mathrm{sec}$ and all other nodes are fixed. Results shown in fig 9 are given in table5.
Table 5: Media Access Delay when 32 nodes fix

\begin{tabular}{|l|l|l|l|}
\hline Speed & $\begin{array}{c}\text { Helbert } \\
\text { Curve } \\
\text { (Media } \\
\text { Access } \\
\text { Delay) }\end{array}$ & $\begin{array}{c}\text { Hexagonal } \\
\text { Trajectory } \\
\text { (Media Access } \\
\text { Delay) }\end{array}$ & $\begin{array}{c}\text { Square } \\
\text { Traject- } \\
\text { ory } \\
\text { (Media } \\
\text { Access } \\
\text { Delay) }\end{array}$ \\
\hline $5 \mathrm{~m} / \mathrm{sec}$ & $0.013 \mathrm{sec}$ & $0.013 \mathrm{sec}$ & $\begin{array}{l}0.016 \\
\mathrm{sec}\end{array}$ \\
\hline $7 \mathrm{~m} / \mathrm{sec}$ & $0.015 \mathrm{sec}$ & $0.013 \mathrm{sec}$ & $\begin{array}{l}0.015 \\
\mathrm{sec}\end{array}$ \\
& & & \\
\hline
\end{tabular}

Fig11 shows the results of Media Access Delay for helbert curve, hexagon trajectory and square trajectory when 32 nodes are fixed and all other nodes are moving with speed of $5 \mathrm{~m} / \mathrm{sec}$ and $7 \mathrm{~m} / \mathrm{sec}$. Results shown in fig 10 are given in table6.

Table 6: Media Access Delay when 32 nodes fix

\begin{tabular}{|l|l|l|l|}
\hline Speed & $\begin{array}{c}\text { Helbert } \\
\text { Curve } \\
\text { (Media } \\
\text { Access } \\
\text { Delay) }\end{array}$ & $\begin{array}{c}\text { Hexagonal } \\
\text { Trajectory } \\
\text { (Media Access } \\
\text { Delay) }\end{array}$ & $\begin{array}{c}\text { Square } \\
\text { Traject- } \\
\text { ory } \\
\text { (Media } \\
\text { Access } \\
\text { Delay) }\end{array}$ \\
\hline $5 \mathrm{~m} / \mathrm{sec}$ & $0.013 \mathrm{sec}$ & $0.015 \mathrm{sec}$ & $\begin{array}{l}0.011 \\
\mathrm{sec}\end{array}$ \\
\hline $7 \mathrm{~m} / \mathrm{sec}$ & $0.015 \mathrm{sec}$ & $0.015 \mathrm{sec}$ & $\begin{array}{l}0.012 \\
\mathrm{sec}\end{array}$ \\
\hline
\end{tabular}

\section{CONCLUSION AND FUTURE SCOPE}

In this paper the effect of trajectories is analyzed on mesh topology by moving nodes at different speed. To analyze the effect 500 nodes are used which are placed randomly and some nodes move by using different trajectories at different speed. Trajectories used are helbert Space-filling curve, hexagon and outer square trajectory. The performance is analyzed in terms of Throughput, Packet Loss and Media Access Delay. Results have been analyzed once by keeping 32 nodes fixed and all others moving at speed of $5 \mathrm{~m} / \mathrm{sec}$ and 7 $\mathrm{m} / \mathrm{sec}$ and secondly by moving 32 nodes at speed of $5 \mathrm{~m} / \mathrm{sec}$ and $7 \mathrm{~m} / \mathrm{sec}$ and keeping all other nodes fixed. When 32 nodes are kept fixed and all other nodes are moving it has been concluded that the hexagon trajectory performs better as compare to square trajectory. Further it has been investigated that when 32 nodes moves and all other nodes are kept fixed, the performance of square trajectory is better at speed of 5 $\mathrm{m} / \mathrm{sec}$ and the performance of helbert curve is better at speed of $7 \mathrm{~m} / \mathrm{sec}$.

\section{REFERENCES}

[1] A. Pennacchia, P. Mazzolai and P. Dario, "Development of a Programmable Sensor Interface for Wireless Network Nodes for Intelligent Agricultural Applications," Proceedings of IE, IEEE Computer and Communications Societies, Sydney, 2005, pp. 1-6.

[2] Yu Chengbo et al, " Reaserch and Application on the coverage range of the ZigBee Protocol", IEEE ,Beijing,20-21,Sept. 2009,pp. 1-4. 
[3] Boris Mihajlov et al., "Overview and Analysis of the Performances of ZigBee based Wireless Sensor Networks", International Journal of Computer Applications Volume 29- No.12,2011, pp. 0975-8887.

[4] Yu-Kai Huang et al. "Distributed Throughput Optimization for ZigBee Cluster-Tree Network" IEEE Transaction On Parallel and Distributed Systems, VOL. 23-No.3, 2012,pp. 513-520.

[5] K. Konstantinos, X. Apostolos, K. Panagiotis and S. George, "Topology Optimization in Wireless Sensor Networks for Precision Agriculture Applications," Sensor Technologies and applications, Velencia, 14- 20 Oct 2007, pp. 526-530.

[6] I.S. Hammodi et al, "A comprehensive performance study of OPNET modeler for ZigBee WSN" IEEE, Cardiff,Wales,15-18 Sept.2009, pp. 357-362.

[7] Harsh Dhaka et al, "Impact of Coordinator Mobility on the throughput in a Zigbee Mesh Networks" IEEE,Patiala,19-20 Feb. 2010,pp. 279-284.

[8] Ms. Sonal J. Rane, "A Simulation Study of Behaviour of Mobile Zigbee Node" (IJSRET) Volume 1Issue6,September 2012, pp.001-003.

[9] S. R. Ramyah , "Load Density Analysis of Mobile Zigbee Coordinator in Hexagonal Configuration"
Wireless Sensor Network, Vol. 4- No. 3,2012,pp. 5964.

[10] Neeti Bisht, et al, "Mobility Based Performance Analysis of Wireless Sensor Networks" International Journal of Computer, Electronics \& Electrical Engineering , Volume 2- Issue 2, 21 Oct. 2010,pp. 15-20.

[11] M. A. M. Vieira, C. N. Coelho, D. C. Jr. Silva and J. M. Mata, "Survey on Wireless Sensor Network Devices," IEEE Conference on Emerging Technologies and Factory Automation Proceedings, Vol. 1, 16-19 Sept. 2003, pp. 537-544.

[12] J. S. Choi and M. Zhou, "Performance Analysis of Zigbee-based body sensor networks," Systems Man and Cybernetics IEEE International Conference, Istanbul, 1013 Oct. 2010, pp. 2427-2433.

[13] Y. Gu, A. Lo, and I. G. Niemegeers, "A survey of indoor positioning systems for wireless personal networks," IEEE Communications Surveys \& Tutorials, vol. 11- no. 1, First Quarter 2009, pp. 13-32.

[14] Ghafoor, Saim, et al. "An efficient trajectory design for mobile sink in a wireless sensor network." Computers \& Electrical Engineering, Vol. 40-no.7 ,Oct. 2014, pp. 2089-2100. 